\title{
Evaluation of Computed Tomography Scan Resolution Power in Detecting Chest Nodules Using Tissue Equivalent Phantom
}

\author{
Vahid Changizi ${ }^{1}$, Samad Moien Azad $^{2}$ and Shadi Davari ${ }^{3}$ \\ ${ }^{1,3}$ Department of Technology of Radiology and Radiotherpay, Allie Medical Sciences School, Tehran \\ Univeristy of Medical Sciences, Tehran, Iran \\ ${ }^{2}$ Islamic Azad University, Pounak Square, Tehran, Iran
}

Correspondence should be addressed to: Vahid Changizi; changizi@sina.tums.ac.ir

Received date: 7 December 2013; Accepted date: 5 April 2014; Published date: 1 September 2014

Academic Editor: Wingpong Chan

Copyright (C) 2014. Vahid Changizi, Samad Moien Azad and Shadi Davari. Distributed under Creative Commons CC-BY 3.0

\begin{abstract}
Introduction: Computed Tomography scan holds much promise for diagnosing most lung solitary nodules; however the CT exposure rates are much higher than the other radiology fields. Besides, there is no sharp border for the size of lung nodules which could be found by CT. Scan. Therefore, there will be an increasing need to find out how we can prevent unnecessary radiation dose to patient while the nodules are clear. Materials and Methods: In this study, a chest phantom including nodules with different sizes and types was designed. Imaging was done by TOSHIBA spiral CT and GE spiral CT with 1, 3 and $5 \mathrm{~mm}$ slices, 80 and $120 \mathrm{kVp}$ and 50, 60, 80 and $100 \mathrm{~mA}$. Results : This study revealed, nodules of $4 \mathrm{~mm}$ in width were noted both in slices with $120 \mathrm{kV}, 50$ and $100 \mathrm{~mA}$, and 3 and $5 \mathrm{~mm}$ thicknesses and in $80 \mathrm{kV}, 60 \mathrm{~mA}$ with $3 \mathrm{~mm}$ thickness. The calcium carbonated particles were noted only in 6,8 , and $10 \mathrm{~mm}$ slice thicknesses; however, a low density of carbonated calcium was noted just in $10 \mathrm{~mm}$ nodules. Conclusion: CT. Scan is a useful technique for detection of lung tumor with sizes of more than 4 $\mathrm{mm}$.
\end{abstract}

Keywords: Chest nodules, CT. Scan, Chest Phantom

\section{Introduction}

Lung is known as a common place for metastases of primary tumors originated extra pulmonary. Since the lung cancer is noted at the end stages of disease, the morbidity and mortality rate related to it is higher than the others. To minimize this rate,

Cite this Article as: Vahid Changizi, Samad Moien Azad and Shadi Davari (2014), "Evaluation of Computed Tomography Scan Resolution Power in Detecting Chest Nodules Using Tissue Equivalent Phantom ", Journal of Radiology Research and Practice, Vol. 2014 (2014), Article ID 583905, DOI: 10.5171/2014.583905 
early diagnosis of lung solitary nodules before spreading metastases to lymph nodes and other organs is of importance. Although chest x-ray makes these solitary nodules be detected, the noise based pitfalls play the barrier role [1].

The lung nodule is a small round mass which enlarges intrapulmonary and can be noted by the physician on a chest x-ray or CT. Scan images. These nodules are smaller than a green pea or as big as a golf ball or even bigger. Mostly they are detected while the patient is being examined for other reasons (e.g. chest x-ray for pneumonia). Using the chest x-ray and lung CT.Scan images, the physician observes the lung solitary nodules, then follows the enlargement through the sequential imaging in 3, 6 or 12 months later and diagnoses the probability of malignancy.

About 500 CT. Scan cases of 60000 for the children less than 15 years old caused cancer in USA (2). Since benign nodules with diameter of less than $5 \mathrm{~mm}$ could change to malignant ones, diagnosis of lung nodules is of importance through chest x-ray. Based on the BEIR health ministry report (2005), even low radiation exposure can increase cancer or other genetic disorders risk especially in children. Therefore, minimizing exposure has been recommended. However, dose rate has inverse relationship on image noise. The increment of image noise could degrade nodules diagnosis [2]. CT. Scan has a reasonable contrast resolution for referring patients with lung nodules indication. However, it delivers high radiation exposure to patient. Dose reduction along with obtaining an acceptable CT image quality could be done by applying:

Shortening the total exposure time $\mathrm{mA}$ and $\mathrm{kV}$ parameters compensation [3].

In recent years some studies have been done using low doses of exposure which lead to the low image qualities (4). However, there is no definite information about how sizes of nodules could be revealed with CT. Scan. It is important to study since exposures with no diagnosis information could cause cancer in patients.

According to the above concerns, we decided to make a lung equivalent tissue including nodules with different sizes and types to evaluate CT. Scan method for detecting chest nodules and to prevent useless exposures and repetitious observations.

\section{Materials and Methods}

In this study, a phantom was designed on the basis of chest phantoms recommended by Capintec, INC including 4, 2.54*25*25 $\mathrm{cm}^{3}$ transparent acrylic planes and one $0.2 * 25 * 25$ $\mathrm{mm}^{3}$ pure aluminum 110 plane and a $0.1 * 25 * 25 \mathrm{~mm}^{3}$ pure aluminum 1100 plane.

Nodules with diameters of 1,2,4,6,8,10 mm in 3 parallel rows were designed. The height of those with the diameters of 1,2 , and $4 \mathrm{~mm}$ was $4 \mathrm{~mm}$ and of those with the diameters of 6,8 , and $10 \mathrm{~mm}$ was 6,8 and $10 \mathrm{~mm}$ respectively (Figures 1-3). 


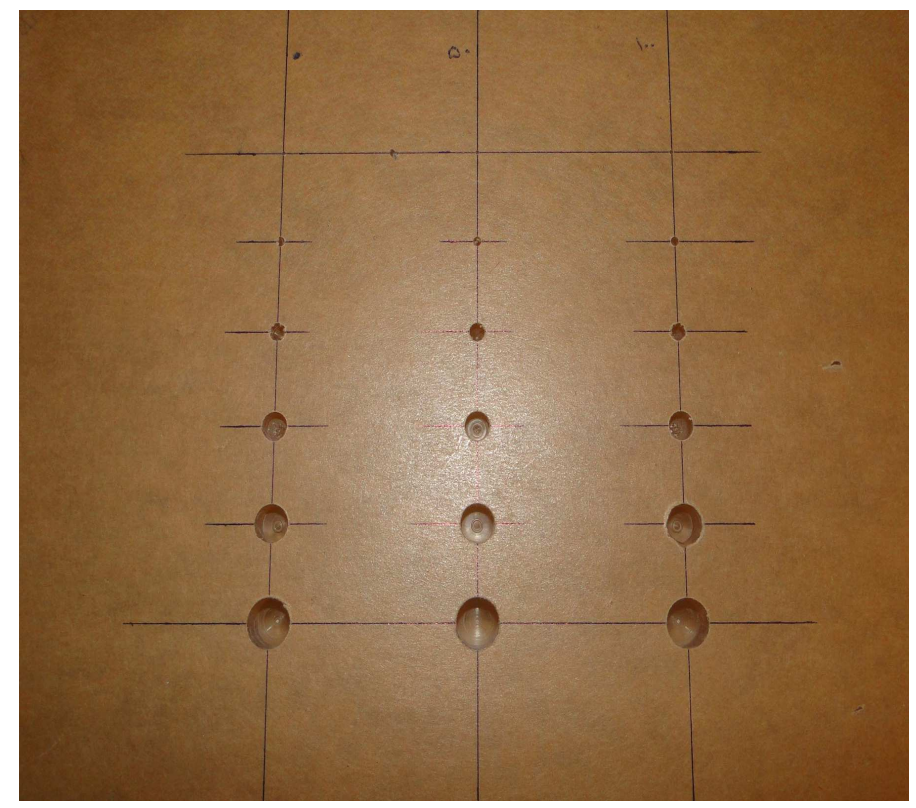

Figure 1: Cylinder-shaped nodules drew out of the acrylic plane with different diameters (up-side view).

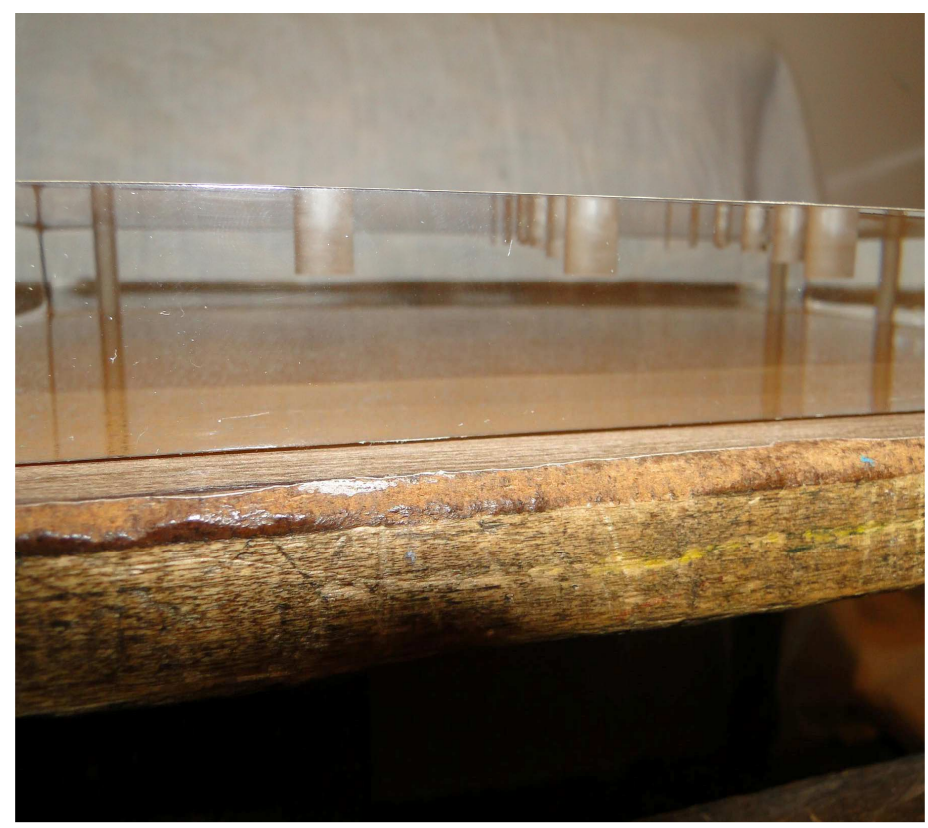

Figure 2: Cylinder-shaped nodules drew out of the acrylic plane with different diameters and height (lateral view). 


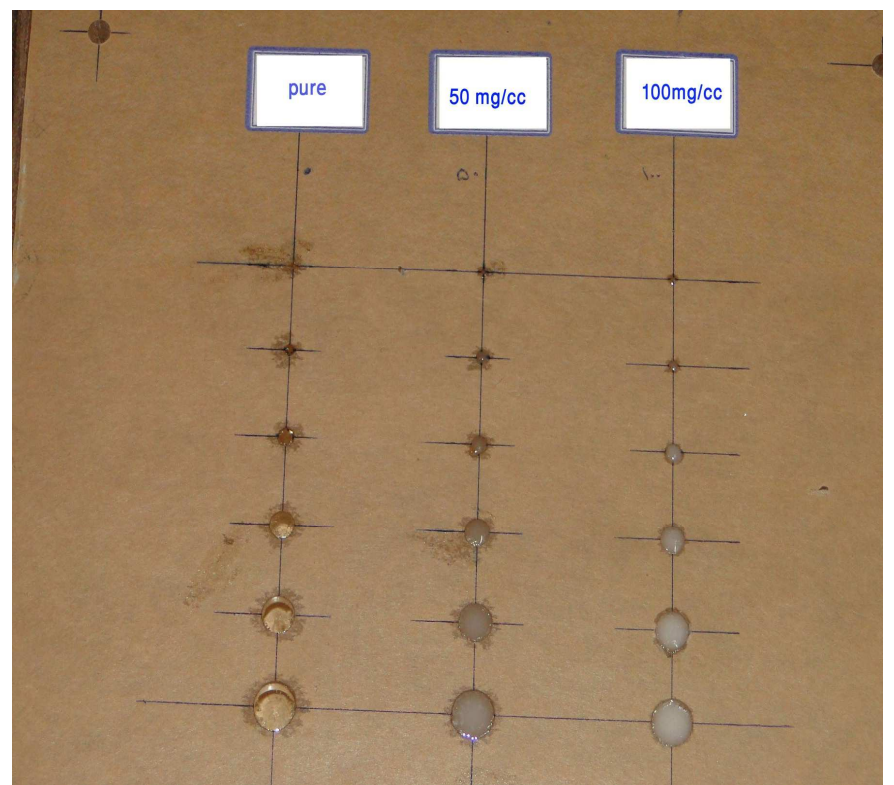

Figure 3: The nodules of the first row were filled with pure epoxy, the second row with epoxy mixed with carbonated calcium with density of $50 \mathrm{mg} / \mathrm{cc}$ and the third row with epoxy mixed with carbonated calcium with density of $100 \mathrm{mg} / \mathrm{cc}$.

Finally, the phantom's pieces were assembled and the completed phantom was used for imaging with spiral CT.Scan.

Imaging of phantom was performed by TOSHIBA spiral CT and GE spiral CT with 1, 3 and $5 \mathrm{~mm}$ slice thicknesses, 80 and $120 \mathrm{kVp}$ and 50, 60, 80 and $100 \mathrm{~mA}$.

\section{Results}

This study revealed nodules of $1 \mathrm{~mm}$ in width that were seen in none of the images (Figure 4). Nodules of $2 \mathrm{~mm}$ in width were noted in 3 and $5 \mathrm{~mm}$ slices with $120 \mathrm{kVp}$ and 50, 60 and $100 \mathrm{~mA}$ (Figure 5). Nodules of 4 $\mathrm{mm}$ in width were noted both in 3 and $5 \mathrm{~mm}$ slice thicknesses with $120 \mathrm{kVp}$ and 50, 100 $\mathrm{mA}$ and in $80 \mathrm{kVp}$ and $60 \mathrm{~mA}$ (Figure 6). 


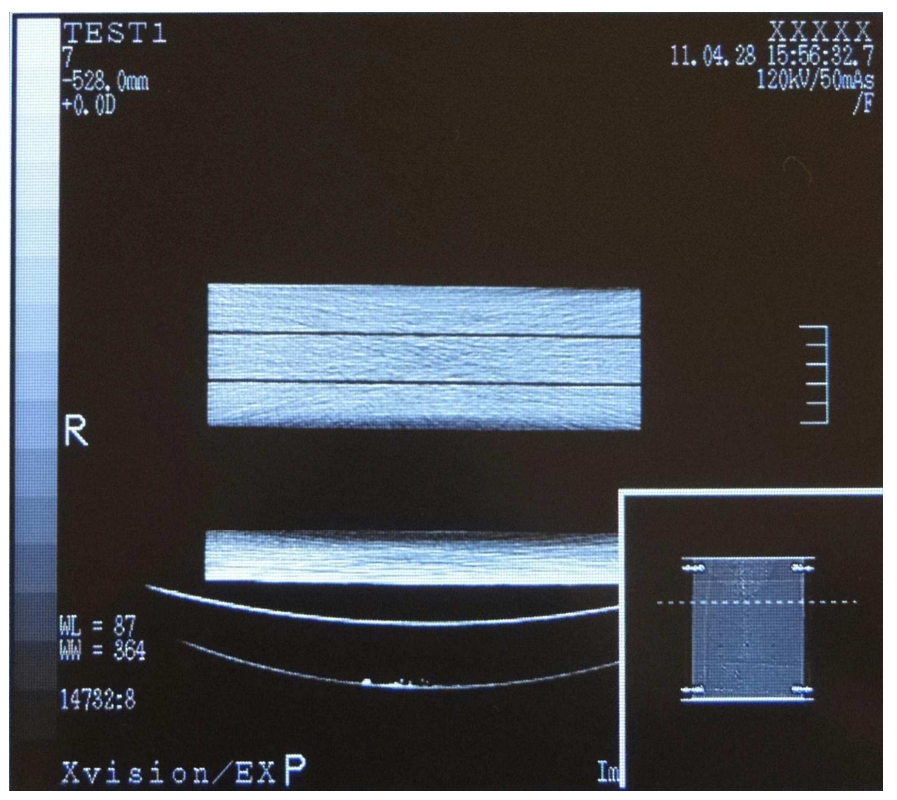

Figure 4: $1 \mathrm{~mm}$ width nodules were seen in none of the images.

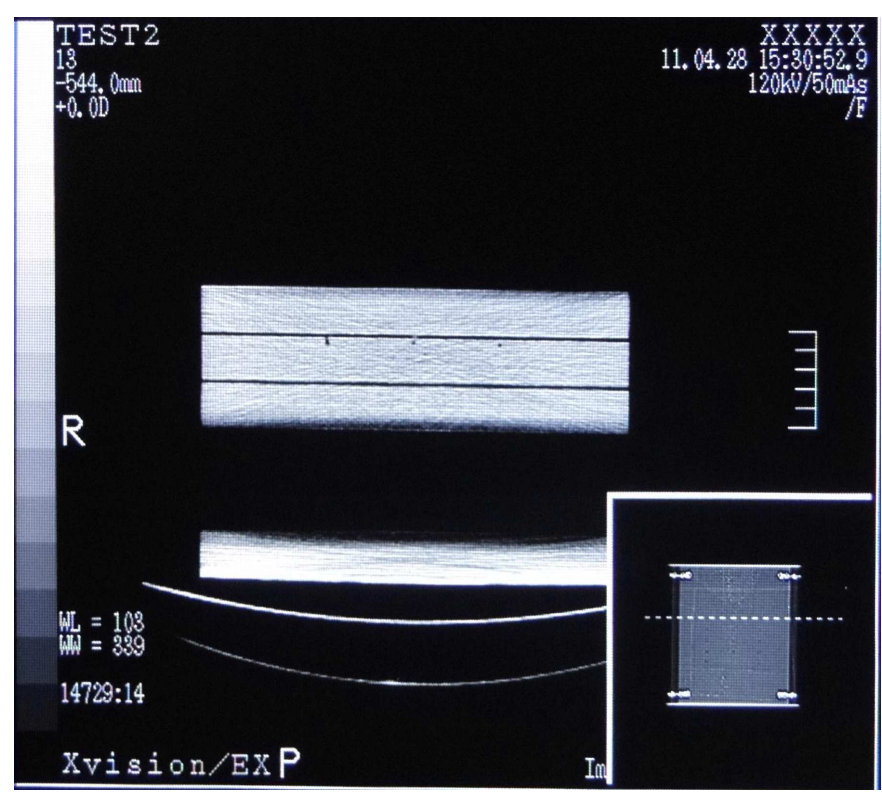

Figure 5: Nodules with diameter of $2 \mathrm{~mm}$ were seen in slices with $120 \mathrm{kV}$ and 50, 60, $100 \mathrm{~mA}$.

Vahid Changizi, Samad Moien Azad and Shadi Davari (2014), Journal of Radiology Research and Practice, DOI: $10.5171 / 2014.583905$ 


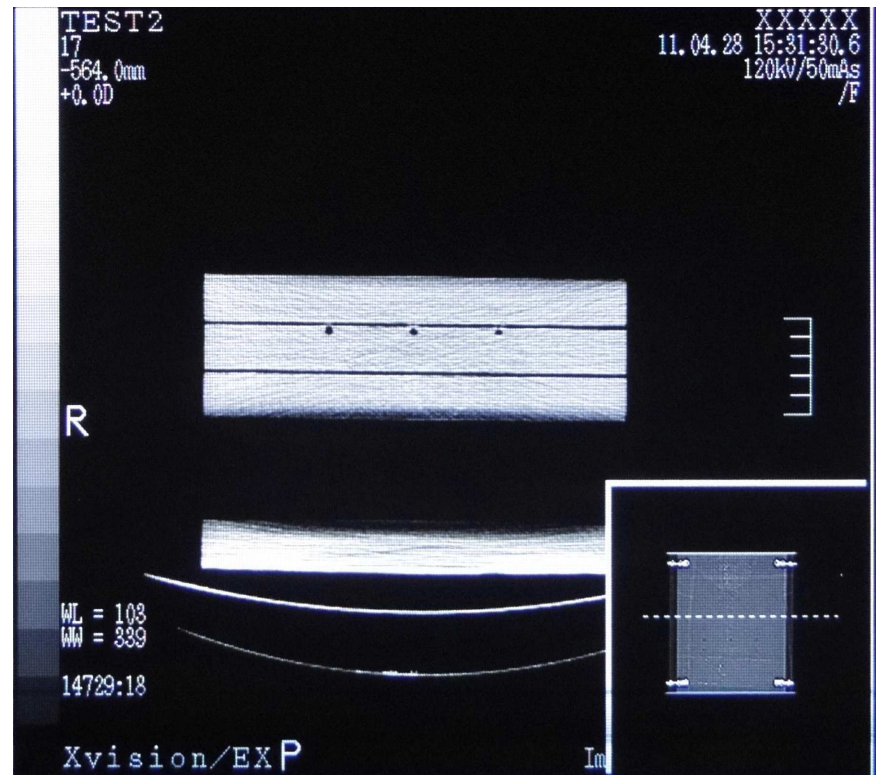

Figure 6: Images with the $4 \mathrm{~mm}$ width nodules.

Nodules of $6 \mathrm{~mm}$ in width were noted in 120 $\mathrm{kVp}$ and 50, $100 \mathrm{~mA}$ with 3 and $5 \mathrm{~mm}$ thicknesses. The nodules larger than $6 \mathrm{~mm}$ were noted in all slices with $120 \mathrm{kV}$. The calcium carbonated particles were noted in nodules with diameters of 6,8 , and $10 \mathrm{~mm}$ but not in smaller nodules; however, the low density of carbonated calcium was noted just in $10 \mathrm{~mm}$ width nodules (Figures 7-9).

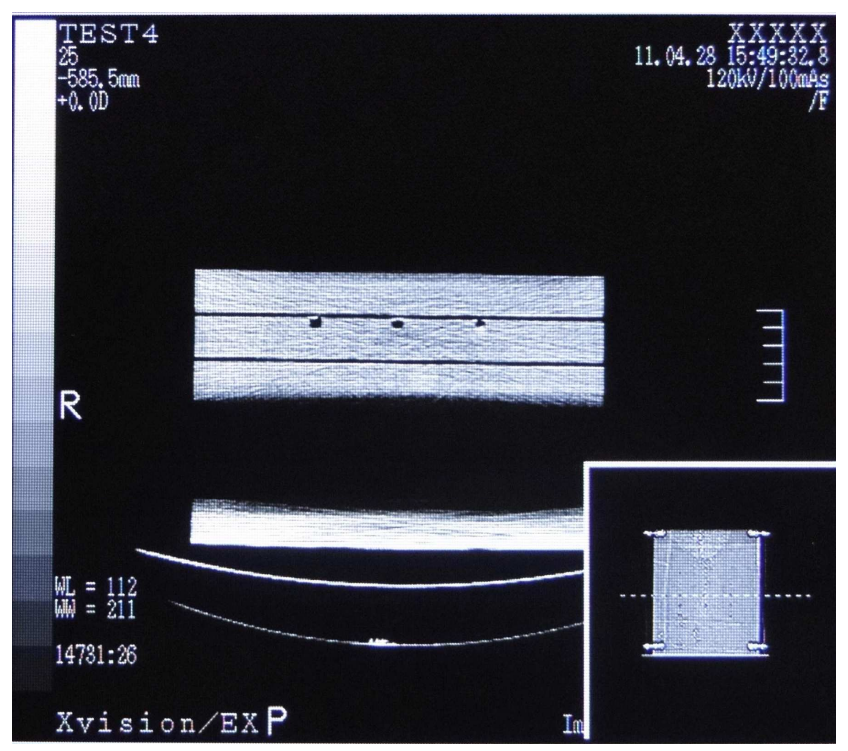

Figure 7: Carbonate calcium can be seen in nodules of $6 \mathrm{~mm}$ with concentration of 100 $\mathrm{mg} / \mathrm{cc}$.

Vahid Changizi, Samad Moien Azad and Shadi Davari (2014), Journal of Radiology Research and Practice, DOI: $10.5171 / 2014.583905$ 


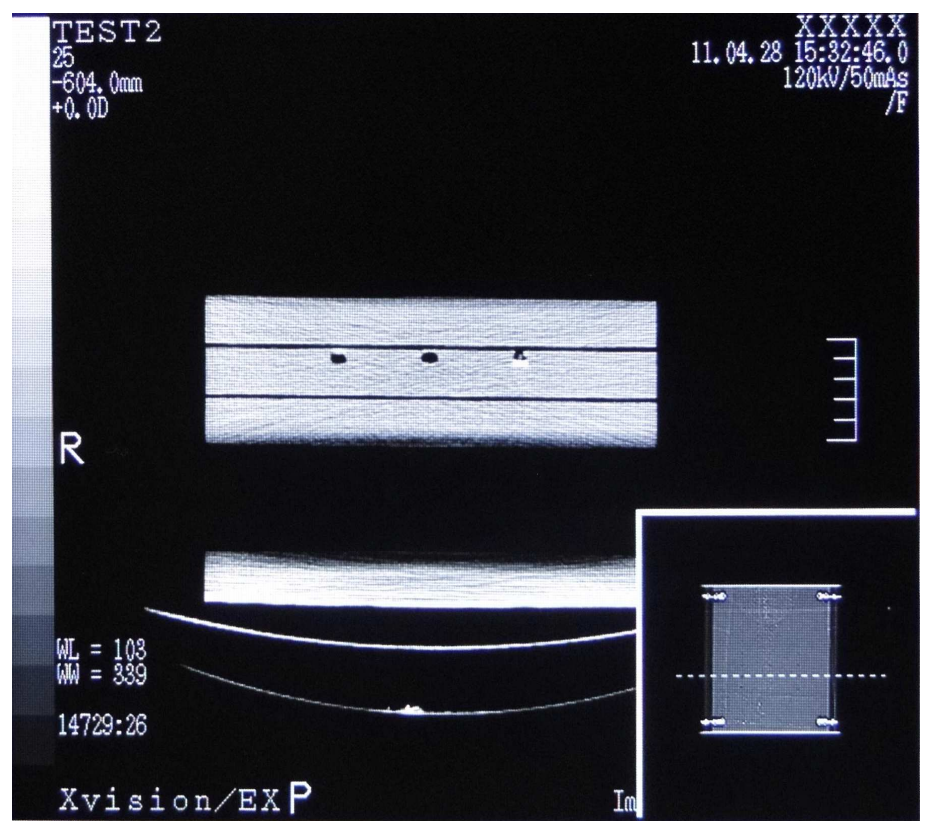

Figure 8: $8 \mathrm{~mm}$ width nodules with noted carbonated calcium particles in the one at the right side (density $100 \mathrm{mg} / \mathrm{cc}$ ).

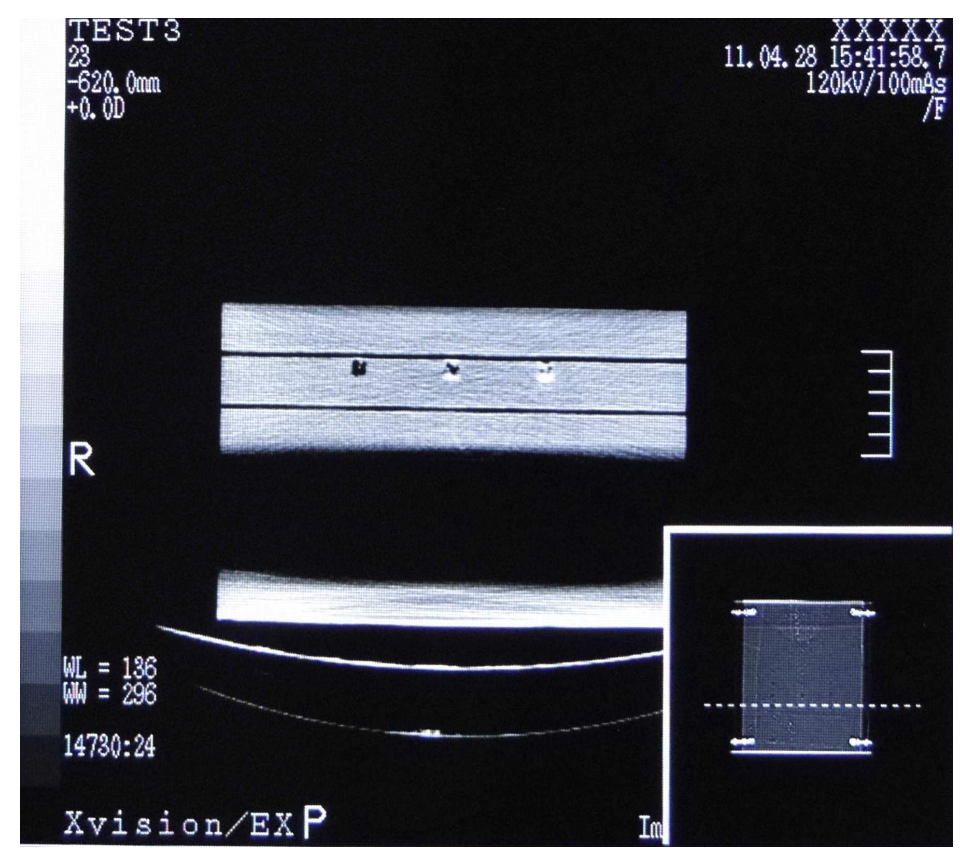

Figure 9: $10 \mathrm{~mm}$ width nodules noted with the carbonated calcium in the middle nodule with low density $(50 \mathrm{mg} / \mathrm{cc})$ and in the one at the right side with high density $(100 \mathrm{mg} / \mathrm{cc})$. 


\section{Discussion}

Based on Siegel's research et al [5], the photon's energy affects the dose rate directly and voltage reduction causes dose reduction in all forms and sizes of designed phantoms. In this study, the nodules of $2 \mathrm{~mm}$ in width were not notable in images with $80 \mathrm{kV}$; therefore, voltage reduction can't be used for dose reduction. Of course for nodules with 4 $\mathrm{mm}$ in width and larger dose reduction could be done through voltage reduction from 120 $\mathrm{kV}$ to $80 \mathrm{kV}$.

Based on Heyer et al [6] study, modern CT scanners use 120 and $140 \mathrm{kV}$ to obtain high quality and standard images. Reducing electric power from $120 \mathrm{kV}$ to $80 \mathrm{kV}$ leads to exposure dose reduction but increases the image noise causing decrease of image resolution incrementally. Our study represented a little reduction of image resolution related to voltage reduction which highly affected on nodules of $2 \mathrm{~mm}$ in width recognition. In other word, although voltage reduction is not considered as an effective factor on image quality but is of importance for nodules less than $4 \mathrm{~mm}$ in width. In these cases there was no difference among 1, 3 and $5 \mathrm{~mm}$ slices. Therefore, the voltage and thickness should not be reduced from $120 \mathrm{kV}$ and $3 \mathrm{~mm}$, respectively.

Punwani et al concluded that dose rate reduction is possible in the recognition of lung nodules with $4 \mathrm{~mm}$ in width. Our study verified their conclusion. This study showed $2 \mathrm{~mm}$ nodules not to be observed in $80 \mathrm{kV}$ but in $120 \mathrm{kV}$, and none of the $1 \mathrm{~mm}$ nodules were noted in the whole study. The main constraint in Punwani et al's study was applying just one slice which caused decreasing nodules recognition sensitivity, but our study represented that sequential slices lead to increment in power of small nodules recognition. Punwani et al showed that the existence of more than one nodule causes the first nodule to be noted by the second. This fact was verified in our research because locating the nodules in 3 parallel rows caused them to be noted beside each other. It can help diagnosis in clinical. In Punwani's research the nodules' location was not of importance in diagnosis but our survey approved its importance. It can be the continuant of Punwani's study.

In Goodsitt et al's survey, the man-made nodules were of carbonated calcium and epoxy with definite density located in a manmade phantom [7]. This study used phantom of acrylic-aluminum planes with cylindershaped nodules having different diameters inside the planes which were filled with carbonated calcium and definite density of epoxy. To obtain higher resolution, they have suggested applying tiny slices with a little interspace for detecting small nodules. It was revealed tinier slices with a little interspace have no significant effect on CT image resolution in large nodules $(8-10 \mathrm{~mm})$.

To reduce image noise in $\mathrm{CT}$, Hiltz and Duzenli have recommended maximizing the $\mathrm{X}$-ray tube voltage, and increase of the mean current, time and image number which adversely cause the heating of X-ray tube during imaging [8].

Using different $m A s$ and a great number of images showed high $\mathrm{mA}(100 \mathrm{~mA})$ in comparison with low $\mathrm{mA}(50 \mathrm{~mA})$ has no considerable effect on image noise and resolution but on increasement of $\mathrm{X}$-ray tube heat.

\section{Conclusion}

Based on this study voltage increasing was more effective than $\mathrm{mA}$ increasing in detecting of small nodules.

We concluded that increasing $\mathrm{mA}$ in high voltages had no significant effect on image quality and nodule detection but would considerably increase absorbed dose in patients. Therefore along with using high voltage to obtain better resolution, it is necessary to decrease $\mathrm{mA}$ for dose reduction. The slice thickness was of little degree in detecting small nodules (less than $4 \mathrm{~mm}$ ). It's not reasonable to use small slice thicknesses, 
since it will be along with increasing patient dose to get a qualified image.

We observed that small calcified nodules (smaller than $4 \mathrm{~mm}$ ) are not detectable in different $\mathrm{kV}$ and $\mathrm{mA}$, and carbonated calcium is noted just in $6 \mathrm{~mm}$ nodules or the larger ones. Identifying the density of carbonated calcium depends on the nodule size because high densities of carbonated calcium are noted in 6-8 $\mathrm{mm}$ nodules but the $10 \mathrm{~mm}$ nodules show different densities.

\section{Acknowledgment}

This project has been supported by Tehran University of Medical Sciences

\section{References}

1. Samei, E., Stanton, A., Stebbins SA, Dobbins, JT.and Lo, JY. (2007), 'Multiprojection Correlation Imaging for Improved Detection of Pulmonary Nodules,' AJR 188, 1239-1245.

2. Punwani, S., Zhang, J., Wareen, D., Greenhalgh, R.and Humphries, P. (2008), 'Paediatric CT: The Effects of Increasing Image Noiseon Pulmonary Nodule Detection,' Pediatr Radiol38,192-201.

3. Li, T., Li, X., Wang, J., Wen, J., Lu, H., Hsieh, J. and Liang, Z. (2004),'Nonlinear Sinogram Smoothing for Low Dose X-Ray CT,' IEEE
Transactions on Nuclear Science 51, 25052513.

4. Imai, K., Ikeda, M., Wada, S., Enchi, Y.and Niimi, T. (2007),'Analysis of Streak Artefacts on CT Images Using Statistics of Extrems,' The British Jornal of Radiology 80, 911-918.

5. Siegel, M., Schmidt, B., Bradley, D., Suess, C.and Hildebolt, C. (2004),'Radiation Dose and Imaging Quality in Pediatric CT: Effect of Technical Factors and Phantom Size and Shape,' Radiology 233, 515-522.

6. Heyer, CM., Mohr, PS., Lemburg, SP. Peter, SA.and Volkmar, N. (2007),'Image quality and Radiation Exposure at Pulmonary CT Angiography with 100 or $120 \mathrm{kVp}$ Protocol:Prospective Randomized Study,' Radiology 245, 577-583.

7. Goodsitt, MM., Chan, HP., Way, TM., Larson, SC., Christodoulou, EG.and Kim, J. (2006),'Accuracy of the CT Numbers of Simulated Lung Nodules Imaged with Multi Detector CT Scanners,' NIH public AccessMed Phys 33, 3006-3017.

8. Hilts, M.and Duzenli, C. (2004),'Image Noise in X-ray CT Polymer Gel Dosimetry,' Journal of Physics Conference Series 3, 252256. 